\title{
THE EFFECT OF GLACIAL CROSS-SECTION ON VERTICAL RESISTIVITY DEPTH SOUNDINGS
}

\author{
By R. W. TAYLOR * and R. J. GREenfield \\ (Department of Geosciences, Pennsylvania State University, University Park, \\ Pennsylvania i6802, U.S.A.)
}

\begin{abstract}
Aвstract. The determination of glacial ice thickness by vertical resistivity depth soundings relies upon the use of theoretical curves which neglect the effect of valley walls. To improve the utility of glacial resistivity measurements an analytical expression is derived for the apparent resistivity determined by a Wenner array oriented parallel to the strike of a layered trough embedded in a perfectly conducting half space. Numerical evaluation of this expression allows the effects of glacial cross-section to be determined. It is shown that the presence of valley walls and layering within the glacier can strongly effect the determination of total ice thickness, and a criterion for the reliable use of plane-layered master curves in the interpretation of field data is established. An apparent resistivity curve calculated for a layered trough is shown to give an excellent fit to field data published by Röthlisberger and Vögtli (1967).
\end{abstract}

RÉsumÉ. L'effet de la forme de la section droite d'un glacier sur les sondages profonds par résistivité verticale. La détermination de l'épaisseur de glace d'un glacier par sondages profonds de résistivité dans le sens vertical repose sur l'utilisation de courbes théoriques qui négligent l'effet des parois de la vallée glaciaire. Afin d'accroître l'utilité des mesures de résistivité glaciaire, on a établi une expression analytique pour la résistivité apparente déterminée par un empilement de Wenner orienté parallèlement à la direction des couches d'une forme en auge stratifiée enchassée dans un demi-espace parfaitement conducteur. Une évaluation numérique de cette expression permet de déterminer les effets de la section droite du glacier. On montre que la présence des parois et celle d'une stratification à l'intérieur du glacier peut fortement affecter la détermination de l'épaisseur totale de la glace; on a établi un mode d'emploi pour un usage digne de confiance de courbes directrices pour glacier à stratification plane dans l'interprétation des données expérimentales. Une courbe de résistivité apparente calculée pour un volume en auge stratifiée, apparaît comme fournissant une excellente introduction aux données expérimentales publiées par Röthlisberger et Vögtli (1967).

Zusammenfassung. Der Einfluss des Gletscherquerschnitts auf Dickenmessungen mit Hilfe des elektrischen Widerstandes in der Vertikalen. Die Bestimmung von Eisdicken aus Messungen des elektrischen Widerstandes in der Vertikalen beruht auf dem Gebrauch theoretischer Kurven, die den Einfluss von Talwänden vernachlässigen. Zur Verbesserung der Zuverlässigkeit von Widerstandsmessungen in Gletschereis wird ein analytischer Ausdruck für den scheinbaren Widerstand hergeleitet, der sich aus einer Wenner-Anordnung mit Orientierung parallel zum Streichen eines geschichteten Troges, der in einen vollkommen leitenden Halbraum eingebettet ist, ergibt. Die numerische Auswertung dieses Ausdrucks erlaubt die Bestimmung des Einflusses des Gletscherquerschnittes. Es zeigt sich, dass das Vorhandensein von Talwänden und Schichtung im Gletscher die Ermittlung der Eisdicke stark beeinflussen kann. Für den zuverlässigen Gebrauch von Ausgangskurven für ebene Schichtung bei der Interpretation von Feldbeobachtungen wird ein Kriterium aufgestellt. Für eine Kurve des scheinbaren Widerstandes in einem geschichteten Trog ergibt sich hervorragende Übereinstimmung mit Daten, die von Röthlisberger und Vögtli (1967) veröffentlicht wurden.

\section{Introduction}

Vertical resistivity depth soundings provide an attractive geophysical means for the determination of glacial ice thickness and have been successfully employed in a number of studies (Röthlisberger, 1967 ). The interpretation of field data, which may be performed at the field site, consists of comparing the accumulated measurements with theoretical or master curves from which the ice thickness may be directly inferred. Details of this procedure are found in Van Nostrand and Cook (1966). The master curves utilized in the interpretation of glacial data are calculated for plane-layered models and do not take into account the troughlike shape of valley glaciers. Röthlisberger ( 1967 ) recognized the possible significance of the trough-like shape, resulting from the presence of steep valley walls, and attempted to estimate corrections to the plane-layered curves through the results of an analogue model study. The model employed, however, did not account for a layer of high-conductivity ice overlaying much more resistive ice, which is a typical feature of valley glaciers. In addition the effects of varying the ratio of ice thickness to glacier width was not investigated in detail. Thus the correction he obtained with the analogue model was limited to the specific model conditions.

\footnotetext{
* Present address: Environmental Research Laboratory, NOAA, Boulder, Colorado 80302, U.S.A.
} 
A more general theoretical or experimental treatment of the effect of glacial cross-section does not appear to exist, although Carpenter (1955) presents a method which can be used to determine the presence of lateral inhomogeneities.

In view of the utility of vertical resistivity profiles in glacial studies it would appear desirable to obtain master curves more appropriate to typical valley glacier cross-sections. While a finite difference method could be employed to generate such master curves (Madden, unpublished; Jepsen, unpublished) the comparatively simple cross-sectional geometry and relatively homogeneous nature of valley glaciers renders the problem amenable to treatment as a boundary-value problem. Since they are rapidly calculated, the analytical solutions obtained in this manner may then be used to investigate the effect of all involved parameters.

\section{TheORY}

The model of a layered trough embedded in a perfectly conducting half-space (Fig. I) provides a good approximation of a typical valley glacier. The perfectly conducting halfspace is a satisfactory representation of the high conductivity of host rocks in comparison to ice. The two layers within the trough, of resistivity $\rho_{1}$ and $\rho_{2}$ respectively, allow the effect of resistivity contrasts between the ice layers to be examined.

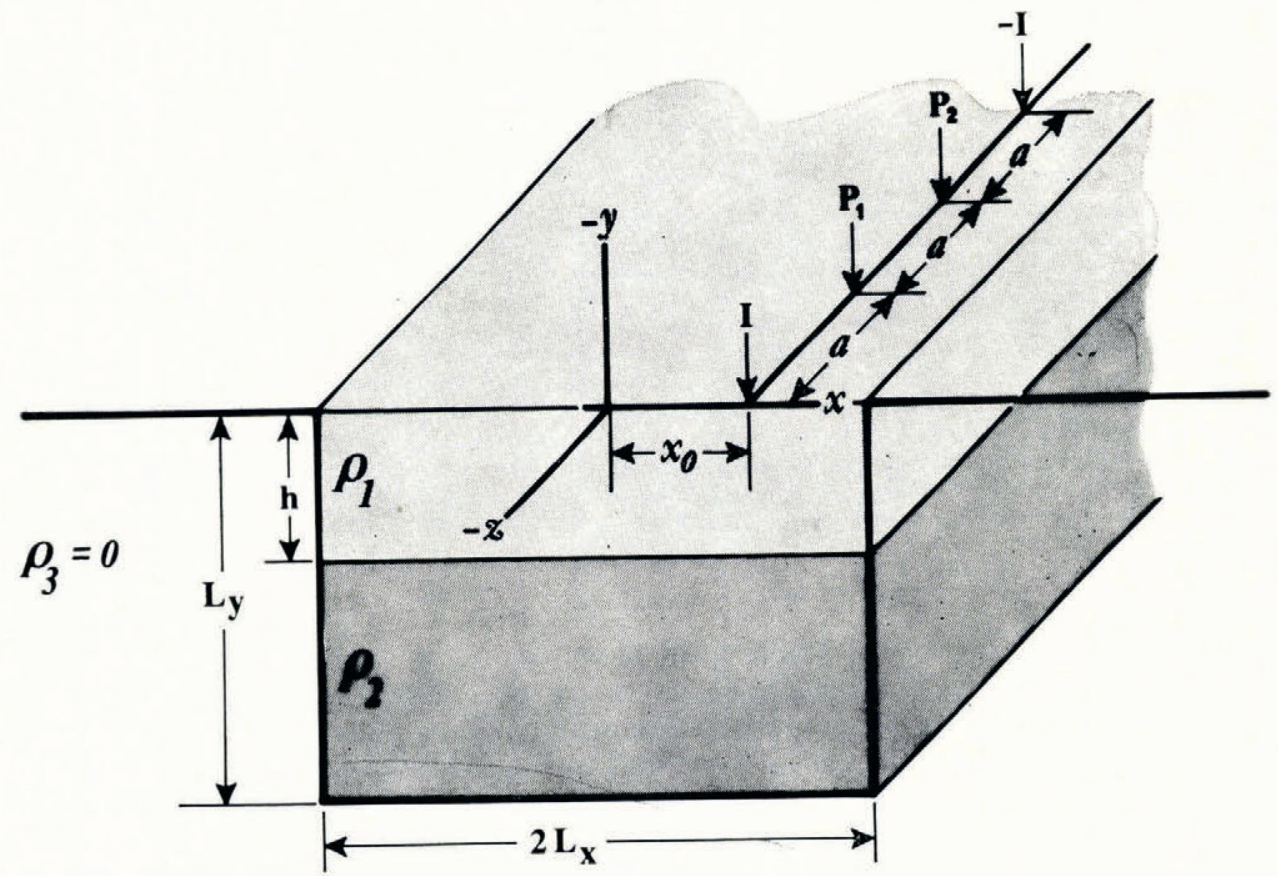

Fig. I. Layered trough model.

The potentials $\phi_{1}(x, y, z)$ and $\phi_{2}(x, y, z)$ obey Laplace's equation, $\nabla^{2} \phi_{1}(x, y, z)=0$ and $\nabla^{2} \phi_{2}(x, y, z)=0$, in the first and second layer, respectively. With a current source $I$ located at the point $\left(x_{0}, 0,0\right)$ the boundary conditions are:

$$
\begin{gathered}
\phi_{\mathrm{I}}\left(L_{x}, y, z\right)=\phi_{2}\left(L_{x}, y, z\right)=\mathrm{o}, \\
\phi_{\mathrm{I}}\left(-L_{x}, y, z\right)=\phi_{2}\left(-L_{x}, y, z\right)=\mathrm{o}, \\
\phi_{\mathrm{I}}(x, y, \infty)=\phi_{2}(x, y, \infty)=\mathrm{o},
\end{gathered}
$$




$$
\begin{aligned}
\frac{\partial \phi_{\mathrm{I}}(x, \mathrm{o}, z)}{\partial y} & =\mathrm{o}, \\
\phi_{1}(x, h, z) & =\phi_{2}(x, h, z), \\
\frac{\mathrm{I}}{\rho_{\mathrm{I}}} \frac{\partial \phi_{1}(x, h, z)}{\partial y} & =\frac{\mathrm{I}}{\rho_{2}} \frac{\partial \phi_{2}(x, h, z)}{\partial y}, \\
\frac{\partial \phi_{1}(x, y, \mathrm{o})}{\partial z} & =\frac{-I \rho_{1} \delta\left(x-x_{0}\right) \delta(v)}{2} .
\end{aligned}
$$

Solution of Laplace's equation by separation of variables (Irving and Mullineux, I959) and evaluation of the arbitrary constants by application of the boundary conditions, yields for the potential in the upper layer:

$$
\begin{aligned}
\phi_{1}(x, y, z)=\sum_{l=1}^{\infty} \sum_{m=1}^{\infty}\left[A_{l m} \cos \lambda_{l} y \sin \right. & \frac{m \pi x}{L_{x}} \exp \left(-\beta_{l m}|z|\right)+ \\
& \left.+B_{l m} \cos \lambda_{l} y \cos \frac{(2 m-\mathrm{I}) \pi x}{2 L_{x}} \exp \left(-\beta_{l m} \star|z|\right)\right]
\end{aligned}
$$

where

$$
\begin{aligned}
\beta_{l m} & =\left[\lambda_{l^{2}}+\left(m / L_{x}\right)^{2}\right]^{\frac{1}{2}}, \\
\beta_{l m} & =\left[\lambda_{l^{2}}+\left\{(2 m-\mathrm{I}) / 2 L_{x}\right\}^{2}\right]^{\frac{1}{2}},
\end{aligned}
$$

$\lambda_{l}$ are the solutions of the eigenvalue equation

$$
\begin{aligned}
& \tan \lambda_{l} h \tan \lambda_{l}\left(L_{y}-h\right)=\rho_{1} / \rho_{2}, \\
& A_{l m}=2 \lambda_{l} \sin \left(m \pi x_{0} / L_{x}\right) \div \\
& \div L_{x} \beta_{l m}\left\{2 h \lambda_{l}+\sin \left(2 h \lambda_{l}\right)-\left[\rho_{\mathrm{I}} \cos ^{2} \lambda_{l} h / \rho_{2}\right.\right.\left.\sin ^{2}\left(\lambda_{l}\left(h-L_{y}\right)\right)\right] \times \\
&\left.\times\left[\sin \left(2 \lambda_{l}\left(L_{y}-h\right)\right)-2 \lambda_{l}\left(L_{y}-h\right)\right]\right\},
\end{aligned}
$$

and

$$
\begin{aligned}
B_{l m}=2 \lambda_{l} & \cos \left\{(2 m-\mathrm{I}) \pi x_{0} / 2 L_{x}\right\} \div \\
& \div L_{x} \beta_{l m} \star\left\{2 h \lambda_{l}+\sin \left(2 h \lambda_{l}\right)-\left[\rho_{1} \cos ^{2} \lambda_{l} h / \rho_{2} \sin ^{2}\left(\lambda_{l}\left(h-L_{y}\right)\right)\right] \times\right. \\
& \times\left[\sin \left(2 \lambda_{l}\left(L_{y}-h\right)-2 \lambda_{l}\left(L_{y}-h\right)\right]\right\} .
\end{aligned}
$$

In obtaining this solution it is necessary to note that the $y$-dependent eigenfunction obeys:

where

$$
\begin{gathered}
\int_{0}^{h} \cos \lambda_{i} y \cos \lambda_{j} y \mathrm{~d} y+\frac{\rho_{1}}{\rho_{2}} \int_{h}^{L_{y}} \frac{\cos \lambda_{i} h \cos \lambda_{j} h \sin \lambda_{i}(y-h) \sin \lambda_{j}\left(y-L_{y}\right)}{\sin \lambda_{i}\left(h-L_{y}\right) \sin \lambda_{j}\left(h-L_{y}\right)} \mathrm{d} y=d, \\
d= \begin{cases}\mathrm{o} & i \neq j \\
G & i=j\end{cases}
\end{gathered}
$$

$$
G=\frac{h}{2}+\frac{\sin 2 \lambda_{i} h}{4 \lambda_{i}}+\frac{\rho_{1}}{\rho_{2}}\left[\frac{\cos \lambda_{i} h}{\sin \lambda_{i}\left(h-L_{y}\right)}\right]^{2}\left[\frac{L_{y}-h}{2}-\frac{\sin 2 \lambda_{i}\left(L_{y}-h\right)}{4 \lambda_{i}}\right] .
$$

For purposes of numerical evaluation it should also be noted that the eigenvalues $\lambda_{i}$ are independent of $m$.

The above expression for the potential in the upper layer may be used in any of the definitive expressions for apparent resistivity $\rho_{\mathrm{a}}$. For the Wenner configuration of Figure I this yields:

$$
\rho_{\mathrm{a}}=\frac{2 \pi a}{I}\left\{2 \phi_{\mathrm{I}}\left(x_{0}, \mathrm{o}, a\right)-2 \phi_{\mathrm{I}}\left(x_{0}, \mathrm{o}, 2 a\right)\right\}
$$


where $a$ is the electrode spacing. Hence

$$
\frac{\rho_{\mathrm{a}}}{\rho_{\mathrm{I}}}=4 \pi a \sum_{l=1}^{\infty} \sum_{m=\mathbf{1}}^{\infty} \begin{gathered}
A_{l m}\left[\mathrm{I}-\exp \left(-\beta_{l m} a\right)\right] \sin \left(m \pi x_{0} / L_{x}\right) \exp \left(-\beta_{l m} a\right)+ \\
\left.+B_{l m} \cos \left\{(2 m-\mathrm{I}) \pi x_{0} / 2 L_{x}\right\}\left[\mathrm{I}-\exp \left(-\beta_{l m} \star a\right)\right] \exp \left(-\beta_{l m} \star a\right)\right\} .
\end{gathered}
$$

The expression for $\rho_{\mathrm{a}}$ converged rather slowly at small $a$ spacings, but provided no serious obstacle to numerical evaluation.

Apparent resistivity and the effect of the valley walls

The effect of the valley walls for a constant conductivity contrast, $K=\rho_{1} / \rho_{2}$, and layer thickness $h$ is to shift the peak of the $\rho_{\mathrm{a}}$ curve towards smaller $a$ spacings (Figures 2 and 3 ). The effect of this shift is to decrease the estimated ice thickness. In both Figures 2 and 3 there exists a value of $L_{x} / L_{y}$ which is the minimum value the ratio may have without significantly affecting the apparent resistivity curves. Denoting the minimum value of the ratio by $L_{\min }$ it is evident from Figures 2 and 3 that $L_{\mathrm{min}}$ is dependent upon the Cagniard parameter $\alpha$ defined as,

$$
\alpha=h K /\left(L_{y}-h\right) \text {. }
$$

Thus, in Figure 2 with $\alpha=$ I I.I, the valley walls will affect the apparent resistivity curves if

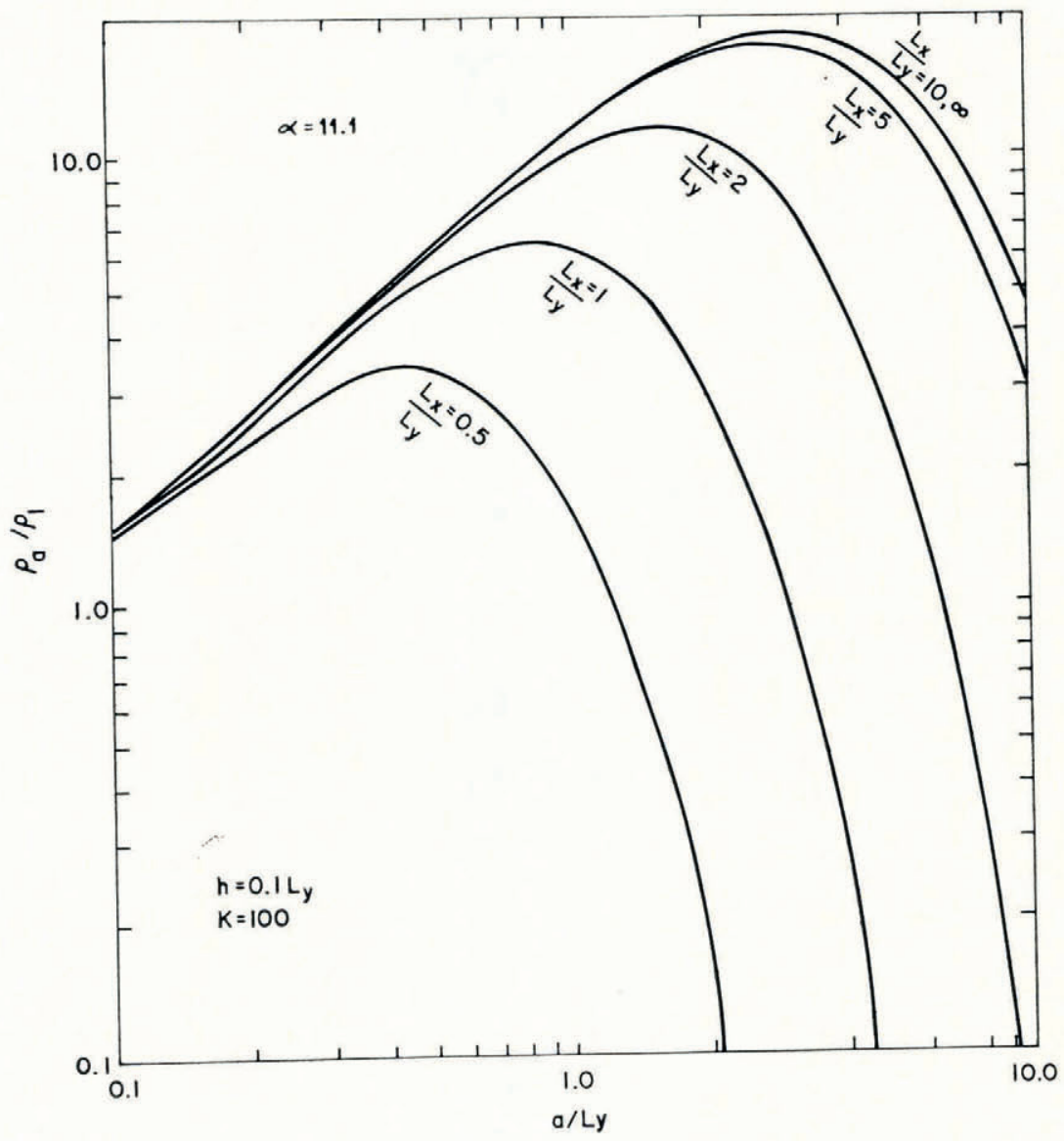

Fig. 2. Apparent resistivity versus a spacing. 


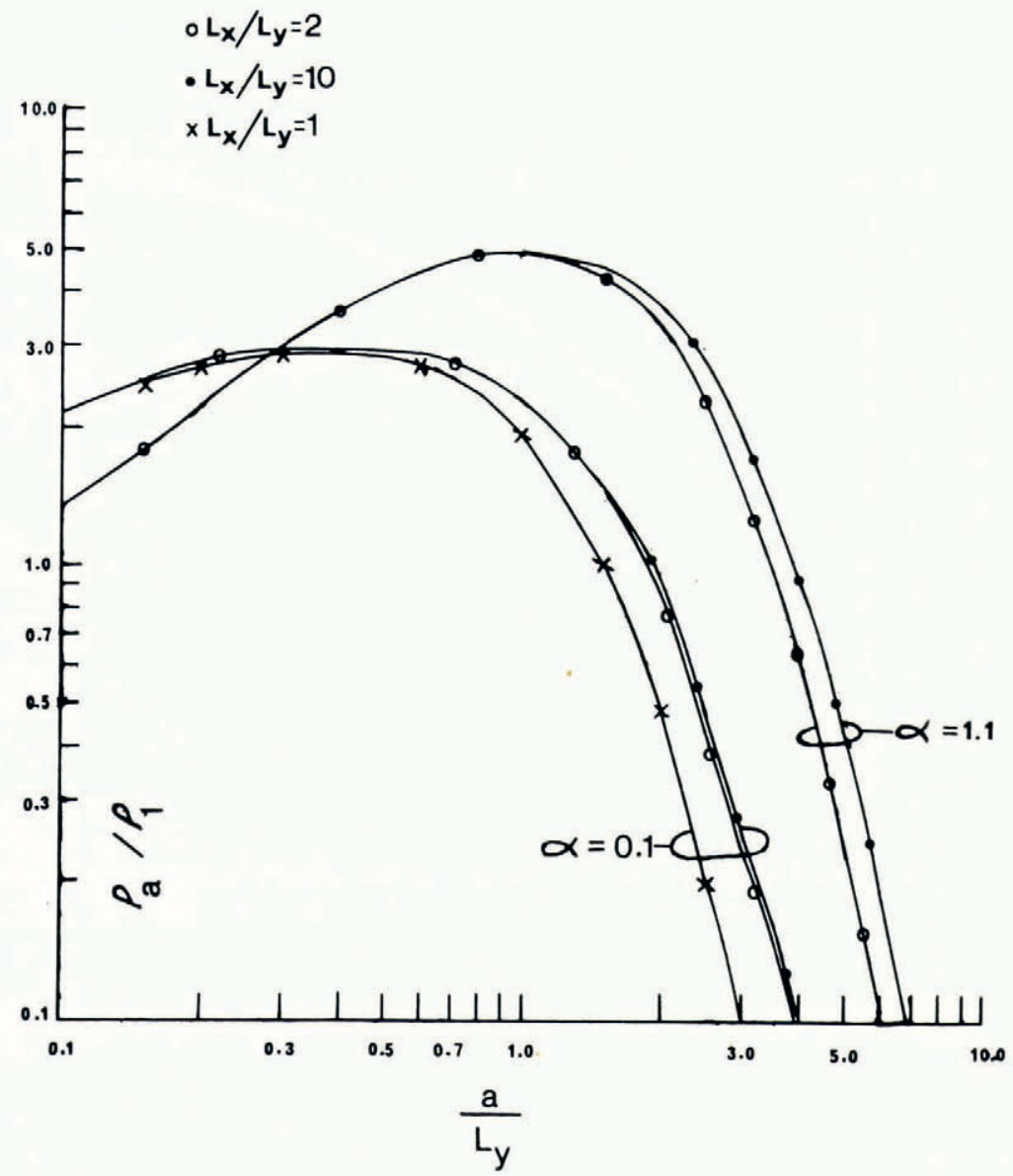

Fig. 3. Apparent resistivity versus a spacing.

$L_{\min }<$ Io while in Figure 3 with $\alpha=0$. I the apparent resistivity will be affected only if $L_{\min }<\mathrm{r} .5$. This is exactly the effect anticipated by Röthlisberger ( 1967$)$. Without attempting to be exhaustive the apparent resistivity curves were generated for several values of $\alpha$, obtained with various combination of $h$ and $K$ and from these a value of $L_{\min }$ selected. Several of these models are listed in Table I. The selected values of $L_{\min }$ versus $\alpha$ are shown in Figure 4. A reasonable rule for the use of plane layered master curves in the interpretation of field data is that the ratio $L_{x} / L_{y}$ appropriate for the data be greater than $L_{\min }$ of Figure 4 .

TABle I. LAYER THICKNESS, CONTRASTS, $\alpha$ AND $L_{\min }$ FOR MODELS CONSIDERED

\begin{tabular}{lrcr}
$h / L_{y}$ & \multicolumn{1}{c}{$\kappa$} & $\alpha$ & $L_{\min }$ \\
0.03 & 3.3 & 0.102 & 1.5 \\
O.1 & 10.0 & 1.11 & 4.0 \\
0.03 & 33.0 & 1.02 & 4.0 \\
0.1 & 100.0 & I I.1 & 10.0
\end{tabular}




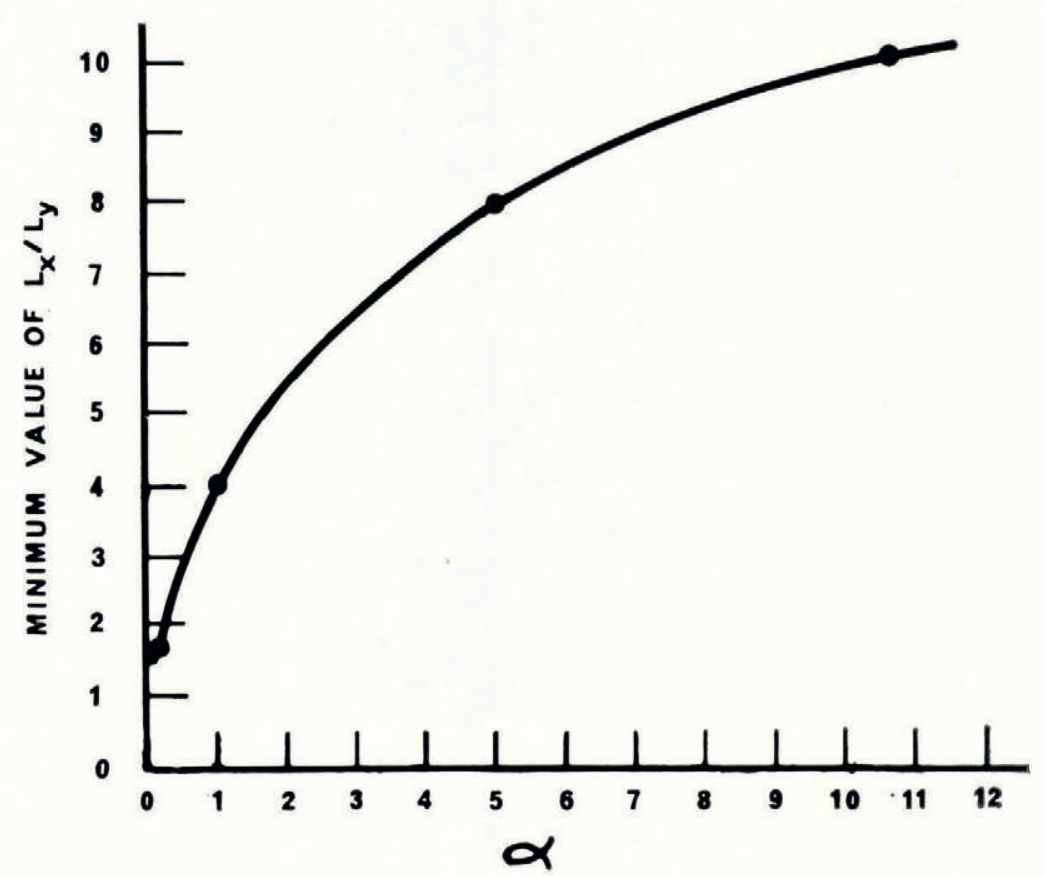

Fig. 4. Minimum value of $L_{x} / L_{y}$ needed for use of plane layer curves; $L_{x} / L_{y}$ should lie above the curve.

\section{Application to field data}

The necessity of accounting for the valley glacier cross-section in the interpretation of field data is evident from the study of Röthlisberger and Vögtli $(1967)$ on the Unteraargletscher. The ice thickness was known from a previous seismic study of this glacier. This allowed the known ice thickness to be compared with the results of the resistivity survey. Figure 5 shows the field data obtained with a Schlumberger electrode configuration and converted by Röthlisberger and Vögtli to equivalent Wenner measurements through an approximate transformation, and the theoretical curve for two plane layers over a half space calculated by Röthlisberger and Vögtli on the basis of the seismically determined ice thickness. The lack of agreement is evident and, as stated by Röthlisberger and Vögtli, the correct ice thickness could not be determined from the resistivity data.

The known cross-section of the glacier can be approximated by a trough 2.5 depth units wide $\left(L_{x}=\mathrm{I}_{2} 2{ }_{5} L_{y}\right)$ with an upper layer thickness of o.or depth units and a $K$ of 10 . The theoretical curve for this structure is included in Figure 5. The agreement between the field data and theoretical curve is excellent. A comparison of the glacier cross-section determined seismically, taken from Röthlisberger and Vögtli ( 1967 ), and the glacier model from which the master curve of Figure 5 was calculated, is shown in Figure 6. Röthlisberger and Vögtli concluded that the deviation of field data from theoretical curves was the result of inhomogeneities within the ice. On the basis of Figure 5 it is evident that a significant part of the deviation resulted from the presence of the valley walls and layers of the glacier. 


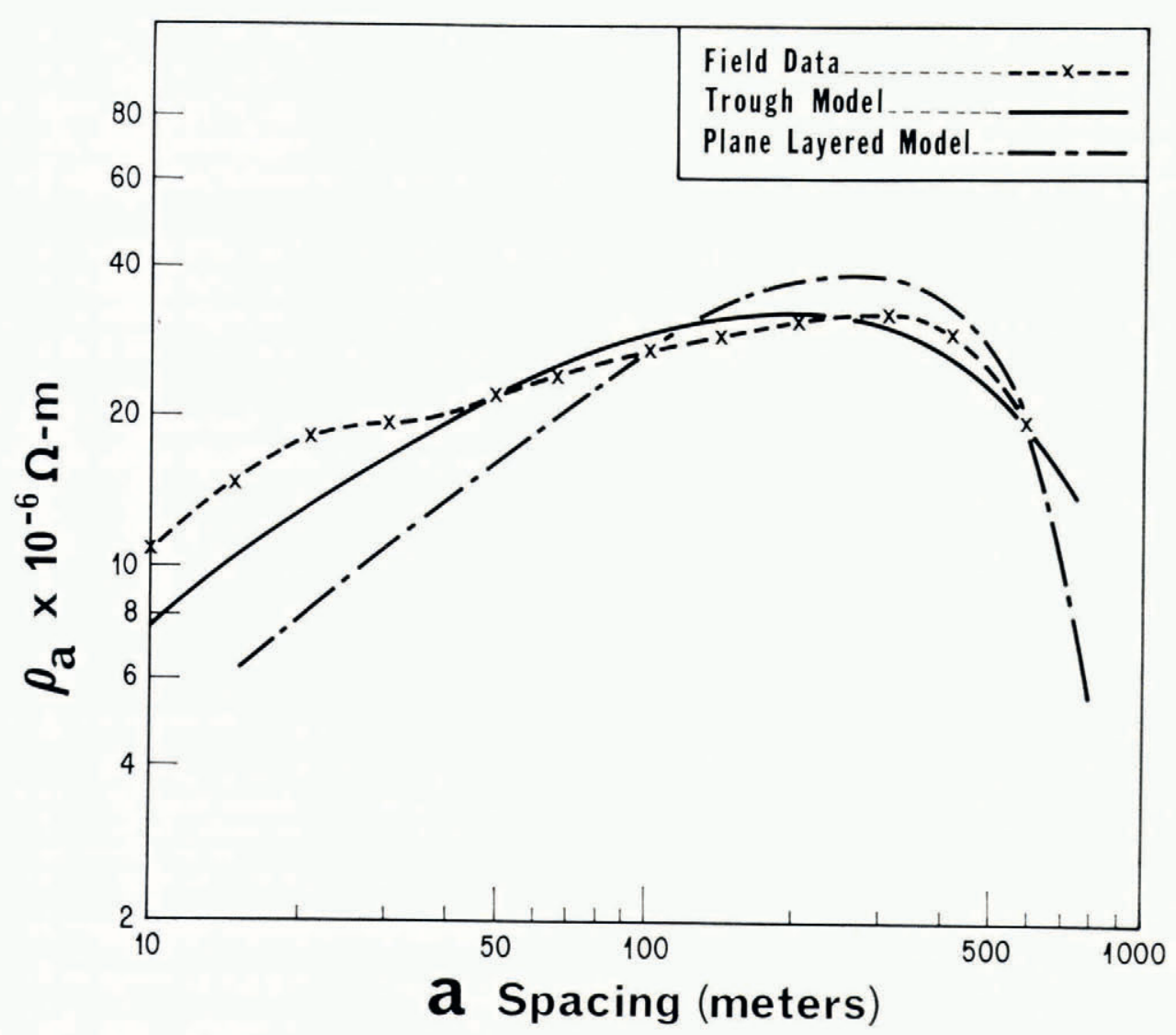
Fig. 5. Apparent resistivity versus a spacing. For trough model $L_{y}=500 \mathrm{~m}, L_{x}=1.25 L_{y}, K=I 00, h / L_{y}=0.0 I$
For plane layered model $\alpha=0.5, L_{y}=350$.

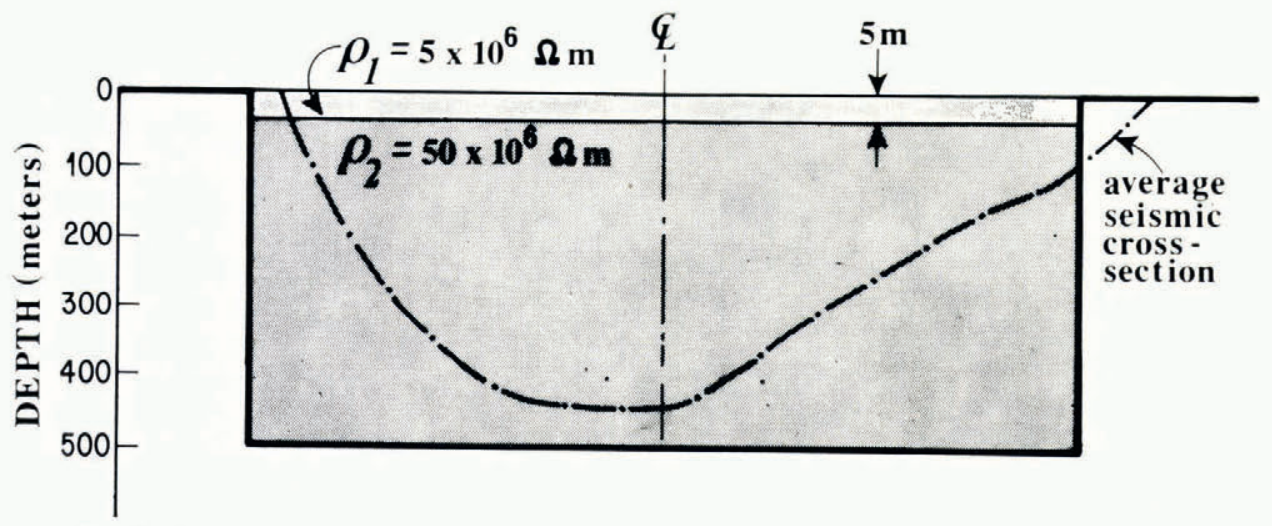

Fig. 6. Comparison of layer trough model fit to Unteraargletscher field data with seismic cross-section. 


\section{Summary and conclusions}

A formulation has been given for calculating the apparent resistivity of a two-layered glacier in a perfectly conducting valley. The analysis could be modified in a straight-forward manner to allow the glacier to have three or more layers as long as the valley floor and walls are essentially perfect conductors. The same type of eigenfunction analysis could also be used to interpret electrical surveys in valleys where the walls and floor are very resistive compared to layered material filling the valley.

Based on "master curves" computed with this formulation, it has been shown that, in order to neglect the presence of the valley walls, the ratio of $L_{x} / L_{y}$ must increase as the Cagniard parameter $\alpha$ increases. A curve showing the minimum allowable values of $L_{x} / L_{y}$ has been given. It is suggested that plane-layer curves not be used to interpret field data unless the $L_{x} / L_{y}$ ratios are greater than the indicated minimum.

Finally we have reinterpreted an electrical profile of Röthlisberger and Vögtli (1967) for the Unteraargletscher. The thickness of the ice as we interpret it, is about $500 \mathrm{~m}$, as compared with the seismic interpretation of $400 \mathrm{~m}$.

MS. received 31 August 1972 and in revised form 26 February 1973

\section{REFERENCES}

Carpenter, E. W. 1955. Some notes concerning the Wenner configuration. Geophysical Prospecting, Vol. 3, No. 4, p. $388-9^{2}$.

Irving, J., and Mullineux, N. 1959. Mathematical physics and engineering. New York, Academic Press.

Jepson, A. F. Unpublished. Relaxation techniques applied to inhomogeneity problems in resistivity and induced polarization. [Paper presented at 1967 meeting of the Society of Exploration Geophysicists, Tulsa, Okla.]

Madden, T. R. Unpublished. Calculation of induced polarization anomalies for arbitrary two-dimensional resistivity structures. [Paper presented at the Symposium on Induced Polarization, University of California, Berkeley, 1 8-19 February 1967.]

Röthlisberger, H. ${ }^{1967}$. Electrical resistivity measurements and soundings on glaciers: introductory remarks. Fournal of Glaciology, Vol. 6, No. 47, p. 599-6o6.

Röthlisberger, H., and Vögtli, K. 1967. Recent D.C. resistivity soundings on Swiss glaciers. Fournal of Glaciology, Vol. 6, No. 47, p. 607-21.

Van Nostrand, R. G., and Cook, K. L. 1966. Interpretation of resistivity data. U.S. Geological Survey. Professional Paper 499 . 